\title{
Agricultura orgânica: características básicas do seu produtor
}

\author{
Eduardo Mello Mazzoleni ${ }^{1}$ \\ Jorge Madeira Nogueira ${ }^{2}$
}

Resumo: A agricultura orgânica é ainda pouco expressiva no Brasil. Sua relevância é, no entanto, crescente, seguindo tendência observada em outros países, em especial na Europa. Este estudo analisa as características básicas do produtor de produtos orgânicos, contribuindo para preencher uma lacuna existente na literatura de economia rural. Utilizando informações primárias sobre agricultores orgânicos da região próxima à cidade de Curitiba, Paraná, identificamos as suas características pessoais e econômicas, por meio de estatística descritiva, análise de correlação e regressão linear múltipla. Os produtores foram divididos em dois grupos: o primeiro com aqueles que ainda estão em conversão para a agricultura orgânica e o segundo grupo composto por produtores orgânicos que já obtiveram a certificação de seus produtos. Os resultados obtidos indicam que alta participação de capital próprio no financiamento da produção e elevado nível de escolaridade são duas das características mais marcantes dos produtores rurais orgânicos paranaenses. Outras características que

\footnotetext{
${ }^{1}$ Mestre em Agronegócios pela UnB. Professor do curso de Administração - habilitação Agroindustrial, da Faculdade da Terra de Brasília (FTB). Analista de Comércio Exterior do Ministério da Agricultura, Pecuária e Abastecimento (MAPA). eduardomazzoleni@agricultura.gov.br

${ }^{2}$ Doutor em Economia pela Universidade de Londres, Inglaterra, e com pós-doutoramento em Economia dos Recursos Naturais na Universidade de Cornell, Estados Unidos. Professor Titular no Departamento de Economia e Professor-Orientador do Mestrado em Agronegócios da UnB. jmn0702@unb.br
} 
influenciam o resultado líquido da atividade são a disponibilidade de mão de obra e a integração de atividades agrícolas, pecuárias e florestais.

Palavras-chave: agricultura orgânica, características dos produtores, fatores críticos.

Classificação JEL: Q01, Q13, Q56, Q58

Abstract: Organic agriculture is still inexpressive in Brazil. Its relevance, however, has been growing significantly, following international trends. This study analyzes basic characteristics of organic producers, contributing to the present level of knowledge on this matter in Brazil. Using primary data on organic farmers of a region close to Curitiba, in the southern state of Paraná, we identify their main personal, technical and economic characteristics. Our sample farmers were divided into two groups: farmers in the stage of conversion toward organic agriculture and farmers already certified as organic producers. Results indicate the influence of the education level and of other professional experiences as key elements to characterize organic producers. Other relevant aspects are labor availability and integration of farming, livestock and forest activities.

Key words: organic agriculture, characteristics of the producers, critical factors.

JEL Classification: Q01, Q13, Q56, Q58

\section{Introdução}

A Terra já foi concebida como uma fonte inesgotável de recursos. Hoje ela é vista como uma "pequena espaço nave" com recursos limitados, exigindo usos eficientes, que maximizem o bem estar social e que busquem a sustentabilidade no longo prazo. A agricultura química, apesar de suas vantagens, traz consigo impactos ambientais negativos significativos. Não se pode conceber a agricultura moderna sem suas variedades super produtivas e adaptadas a um ambiente totalmente controlado com adubos solúveis e agro-químicos para manter esta artificialidade. Os im- 
pactos ambientais desses produtos geralmente não são incorporados nos custos privados de produção, distorcendo os preços de mercado de produtos por ela gerados. A agricultura química gera, portanto, externalidades negativas. O ônus dessas externalidades (degradação e/ou poluição) é arcado pela sociedade como um todo, não pelos produtores privados.

A busca de formas alternativas de produção agrícola tem sido acompanhada por controvérsias. Para alguns, agricultura orgânica é ficção de naturalistas inconseqüentes; para outros ela é uma revolução, a exemplo do que foi a Revolução Verde, por outros. Há ainda posições intermediárias, ressaltando que o processo de transformação sustentável deverá ser paralelo à agricultura moderna (BEZERRA e VEIGA, 2000). Tudo indica que existe um desafiador caminho a ser conquistado na melhora da produtividade e da lucratividade da produção orgânica. Freitas (2002) argumenta que a agricultura orgânica pode reduzir custos e ser tão rentável quanto o sistema químico convencional. Para que esse desafio possa ser enfrentado, é essencial que as características daqueles que atualmente empreendem a agricultura orgânica sejam compreendidas. Só assim poder-se-á decidir se são desejáveis e necessários estímulos para a consolidação deste tipo de agricultura no Brasil.

O desenvolvimento sustentável propõe que as necessidades da presente geração sejam atendidas sem sacrificar a possibilidade que as gerações futuras atendam as suas próprias necessidades. Agir de forma sustentável é estudar, planejar e implementar ações pensando no hoje e no amanhã, abordando os aspectos econômicos, sociais e ambientais, respeitando as diferenças culturais. Essa proposta é inconcebível com o atual nível de desgaste dos recursos naturais provocado pela agricultura química. A agricultura orgânica pode ser um caminho a ser percorrido para a busca da sobrevivência harmônica do ser humano com o seu planeta. No entanto, será que pensando em garantir a manutenção de opções para as gerações futuras, não estamos sacrificando a geração presente?

O presente trabalho analisa uma cadeia de produção orgânica, destacando as características pessoais, técnicas e econômicas relevantes do produtor de agricultura orgânica. O objetivo é caracterizar os agricultores orgânicos de uma área próxima à cidade de Curitiba, Paraná. O artigo está estruturado em cinco seções. Inicialmente são abordados os conceitos e a evolução da concepção atual da agricultura orgânica. Prossegue 
com o relato da origem dos dados e a definição do método utilizado durante a pesquisa. Na seção de Resultados e Discussão são identificadas as características dos produtores orgânicos, separando-os em dois grupos: o dos produtores em processo de conversão para a agricultura e o outro de produtores orgânicos já certificados. Há, ainda, uma seção analisando as composições das despesas totais em relação a variáveis que interferem no resultado financeiro líquido. É realizado diagnóstico dos fatores críticos e das principais forças impulsoras e restritivas desse sistema orgânico de produção. O artigo é encerrado com alguns comentários conclusivos.

\section{Convergência conceitual da 'agricultura orgânica'}

O termo agricultura orgânica é utilizado de forma generalizada nos principais países do mundo. Mencionado em documentos oficiais de organismos internacionais (ONU, UNCTAD, FAO), é também encontrado na legislação brasileira, desde a Instrução Normativa Nº 7, 17/05/1999 (Brasil, 1999), consolidando-se com a recente Lei 10.831, de 23/12/2003 (Brasil, 2003). Para uma melhor compreensão do que é agricultura orgânica é necessário situar como este termo foi forjado e as transformações por que passou ao longo do tempo. Na verdade, é necessário avaliar as transformações que ocorreram no setor agrícola paralelamente à interpretação da história da evolução econômica de uma forma geral. As relações entre o universo amplo e a agricultura são básicas para compreender como se forjou o conceito atual.

A Figura 1 indica que os acontecimentos da Primeira Revolução Agrícola auxiliam o entendimento da grande migração de mão-de-obra para as fábricas na Primeira Revolução Industrial. A tração animal permitiu a passagem do pousio ao cultivo anual, graças ao plantio de forragens e rotação com leguminosas, aproximando a agricultura da pecuária. A integração agricultura e pecuária tornava o novo sistema produtivo dependente de matéria orgânica para fertilização constante da terra. O incremento da diversidade de plantas e a adoção de vários métodos de cultivo permitiram "aumentar a lotação de cabeças de gado nas propriedades, beneficiando a fertilidade dos solos, principalmente os solos fracos.” (EHLERS, 1994, p.11). "O cultivo e a criação de animais formaram progressivamente os alicerces das sociedades européias. E esse longo acúmulo acabou por provo- 
car um dos mais importantes saltos de qualidade da civilização humana: o fim da escassez crônica de alimentos." (VEIGA,1991, p.21).

Já a Segunda Revolução Agrícola é marcada principalmente pela inovação dos fertilizantes químicos. Em 1840, o químico alemão Justus von Liebig publica a teoria da nutrição mineral das plantas. Ehlers (1994), citando Acot, comenta que Liebig é considerado o maior precursor da 'agroquímica', ou seja, da agricultura química moderna, atingindo a estrutura produtiva da Primeira Revolução Agrícola. Do mesmo modo que na revolução industrial, diversas inovações são somadas gradativamente. Quanto mais conhecimento científico e tecnológico era agregado na Segunda Revolução Agrícola, mais crescia o poder do homem de controlar as variáveis da natureza ao interesse produtivo. Ocorre uma especialização cada vez maior, surgindo as monoculturas e, devido aos problemas advindos desse sistema, os agroquímicos.

Figura 1 - Mapa de Evolução de Conceitos

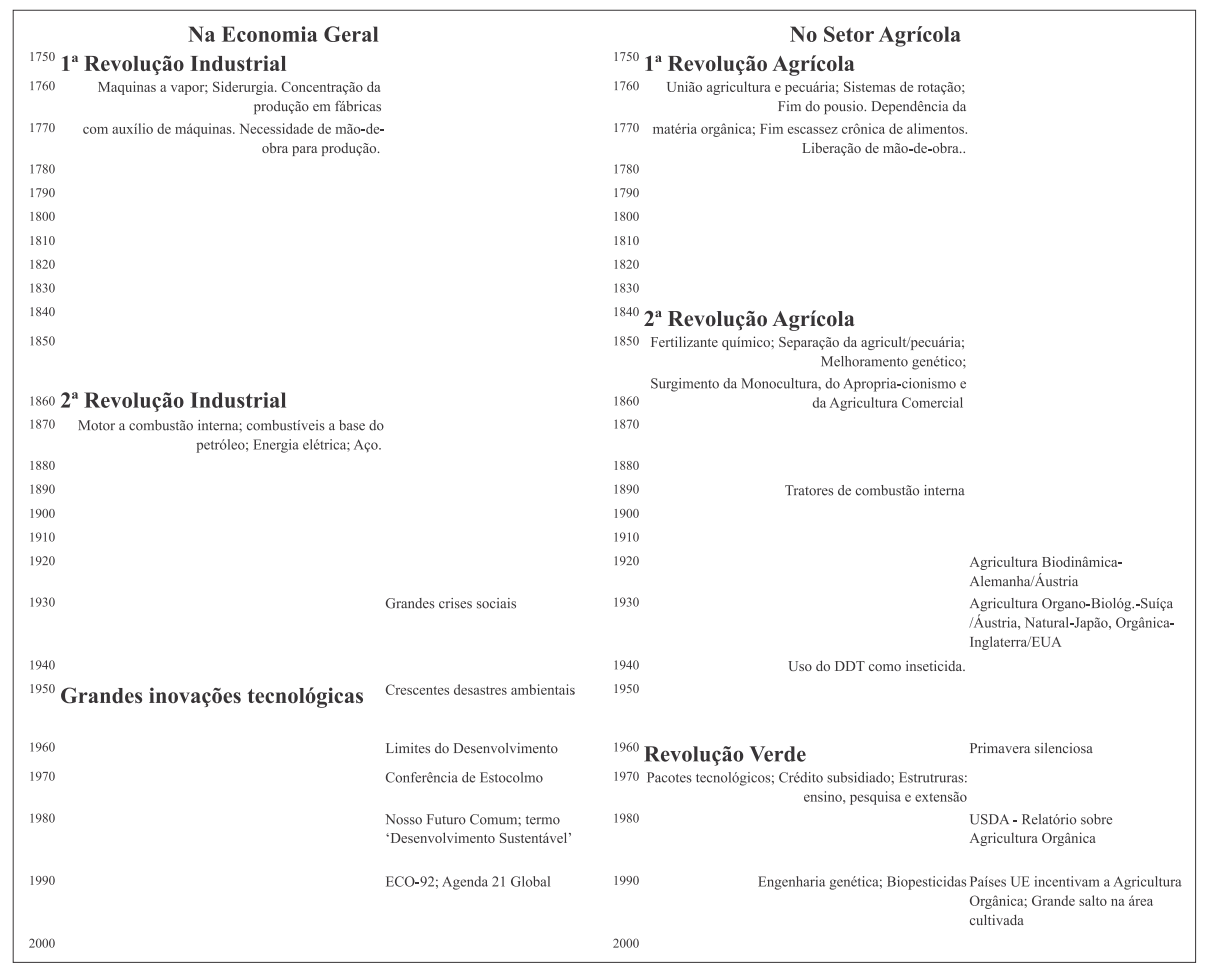

Fonte: Elaborado pelos autores. 
Em resposta às grandes transformações que ocorriam, surgiram diversos movimentos em vários locais do mundo, simultâneos e independentes entre si. Inicialmente foi a agricultura biodinâmica, na Alemanha e Áustria, na década de 1920. Na década seguinte, a agricultura natural no Japão e a agricultura organo-biológica na Suíça e Áustria. Nos anos de 1930 a 1940 surgiu a agricultura orgânica na Grã Bretanha e EUA (DAROLT, 2002). Essas quatro principais correntes de agricultura possuem princípios e histórias distintas. No entanto, conforme afirma Freitas (2002, p. 33): "As quatro vertentes mais expressivas da agricultura alternativa não parecem apresentar características contraditórias.”

Essas visões de uma agricultura que respeitasse o meio ambiente estavam inseridas em um mundo apenas preocupado com o 'crescimento' econômico, entendido os aspectos econômicos e sociais. Ao invés de desenvolver conhecimentos e inovações para produção agrícola sem agressões ecológicas, o mundo científico e empresarial caminhou, ou melhor, correu para o outro lado. Neste universo, as prioridades gerais eram o aprofundamento das características da Segunda Revolução Agrícola, buscando através da tecnologia o controle sobre a natureza. O resultado desses esforços culminou com a Revolução Verde.

Todas as inovações tecnológicas verticais (setor industrial agrícola) e transversais (setores da química, genética, mecânica) são reunidas por volta de 1960 e 1970 e direcionadas para agricultura, surgindo a Revolução Verde. Essa revolução é um conjunto homogêneo de práticas tecnológicas (variedades geneticamente melhoradas, fertilizantes químicos, agrotóxicos, irrigação e motomecanização), chamado de pacote tecnológico, que viabilizou, em larga escala, os sistemas monocultorais. Esta concepção era a esperança ilimitada de combate à miséria no mundo. Instituições internacionais e governos dos países subdesenvolvidos se lançaram de corpo e alma nesta empreitada. Nesta época o desprezo pela agricultura orgânica era marcante (EHLERS, 1994).

A Revolução Verde se predispôs a dominar a natureza. Esta modalidade de agricultura é simplificada a ponto de adequar qualquer meio ambiente para o gerenciamento padronizado por pacotes tecnológicos. Porém, a euforia do caminho seguro logo mostrou seus equívocos: "a erosão e a perda da fertilidade dos solos; destruição florestal; a dilapidação do patrimônio genético e da biodiversidade; a contaminação dos so- 
los, da água, dos animais silvestres, do homem, do campo e dos alimentos”. (EHLERS, 1994, p. 24). A percepção dos problemas é praticamente simultânea aos primeiros efeitos da Revolução Verde (ALTIERI, 2002).

Em 1980 surge a Teoria da Trofobiose, definindo que os agroquímicos provocam uma ação nefasta sobre o metabolismo da planta, rompendo a resistência natural desta. (CHABOUSSOU, 1987). A percepção da insustentabilidade da Revolução Verde pode ser observada pelo fato de, poucos anos após, um secretário do Departamento de Agricultura dos Estados Unidos (USDA) ter ridicularizado a agricultura orgânica (1971); outro secretário, em 1980, publicou o Relatório e Recomendações sobre Agricultura Orgânica (USDA, 1984). Era uma época de denúncias, dúvidas e suposições como nos mostra Hess (1980, p. 45): "Chegamos assim a um ponto básico: É possível conciliar o desenvolvimento tecnológico com o equilíbrio ecológico?”

Mais ou menos na mesma época, observava-se o início de mudança de perspectiva também no Brasil. Francisco Graziano Neto (1982, p. 9) relata que em 1977, no $1^{\circ}$ Congresso Paulista de Agronomia, "se lançou, de forma patente, a necessidade de se repensar a agricultura brasileira, procurando alternativas de desenvolvimento. [...] Mas outra questão, inteiramente nova, começou a ser levantada: tratava-se das considerações ecológicas.” Não obstante, o avanço do sistema orgânico propriamente dito ocorreu no Brasil a partir de 1992. Seus conceitos iniciais não necessariamente abordavam a questão da justiça social como um aspecto característico de cada sistema produtivo. Hoje, o termo agricultura orgânica possui uma conotação nova e mais abrangente. Nesta condição, a expressão 'agricultura orgânica' abrange todas as demais definições que atentem para o problema de desenvolver a agricultura de forma economicamente viável, social justa e ambiental correta.

\section{Materiais e métodos}

Os dados utilizados no presente estudo foram disponibilizados por Moacir Roberto Darolt ${ }^{3}$. A tese de doutorado, que deu origem a este ban-

3 Trabalho de Moacir Roberto Darolt, intitulado “As Dimensões da Sustentabilidade: Um Estudo da Agricultura Orgânica na Região Metropolitana de Curitiba, Paraná. Tese de doutorado do Curso de Pós-Graduação em Meio Ambiente e Desenvolvimento, da Universidade Federal do Paraná”. 
co de dados, foi um estudo analítico da agricultura orgânica sob diferentes dimensões da sustentabilidade. Isso permitiu avaliações diferentes, com outros enfoques analíticos, da realidade dos agricultores orgânicos paranaenses. As informações de campo foram coletadas para 87 famílias de agricultores ligadas à Associação de Agricultura Orgânica do Paraná (AOPA). Deste total, cerca de 30 famílias foram excluídas basicamente por não apresentarem experiências concretas em agricultura orgânica.

As entrevistas foram realizadas aplicando-se um questionário previamente estruturado e também com questões semi-abertas. Foram gravados e anotados comentários e observações dos agricultores, desta forma, a pesquisa teve também um caráter de entrevista aberta. Foram coletadas informações agroecológicas e socioeconômicas, bem como entrevistas de caráter aberto, dirigidas a outros atores que trabalham no âmbito da região (extensionistas rurais, representantes de prefeituras e da EMATER). Como assinalado, foram coletados dados em 57 unidades de produção, que utilizavam o sistema de olericultura orgânico, pertencente a 12 municípios da região metropolitana de Curitiba (RMC), Paraná.

No trabalho de Darolt (2000), foi utilizada a Análise de Cluster para tipificar as unidades em grupos homogêneos e posterior entendimento da estrutura e funcionamento do sistema de produção orgânico. Com esta metodologia, resultou a formação de 4 grupos, sendo 2 tipos com características de agricultores familiares (orgânicos e em transição) e dois tipos com características empresariais (orgânicos e em transição), como demonstra a Tabela 1 .

Tabela 1 - Agrupamentos dos Produtores criados pela Análise de Cluster

\begin{tabular}{l|l|l|l|l}
\hline & Grupo 1 & Grupo 2 & Grupo 3 & Grupo 4 \\
\cline { 2 - 5 } $\begin{array}{l}\text { Agrupamentos } \\
\text { Siglas }\end{array}$ & $\begin{array}{l}\text { Agricultores } \\
\text { Familiares em } \\
\text { Transição }\end{array}$ & $\begin{array}{l}\text { Agricultores } \\
\text { Familiares } \\
\text { Orgânicos }\end{array}$ & $\begin{array}{l}\text { Empresários } \\
\text { Agrícolas } \\
\text { Orgânicos }\end{array}$ & $\begin{array}{l}\text { Empresários } \\
\text { Agrícolas em } \\
\text { Transição }\end{array}$ \\
\cline { 2 - 5 } & AFT & AFO & EAO & EAT \\
\hline $\begin{array}{l}\text { Número de } \\
\text { Produtores }\end{array}$ & $\mathrm{N}=32$ & $\mathrm{~N}=20$ & $\mathrm{~N}=03$ & $\mathrm{~N}=02$ \\
\hline $\begin{array}{l}\text { Percentual de } \\
\text { Produtores }\end{array}$ & $56,1 \%$ & $35,0 \%$ & $5,4 \%$ & $3,5 \%$ \\
\hline
\end{tabular}

Fonte: Elaborado pelos autores, baseado nos dados fornecidos por Darolt. (2000) 
A coleta dos dados econômicos referentes à produção vegetal e animal foi mensal, em função de alguns aspectos básicos. Primeiro, porque os dados foram obtidos em registros cross-section, ou seja, utilizado um recorte temporal entre os meses de novembro/ (???)e fevereiro, o que dificultaria extrapolar os valores para todo o ano agrícola. Segundo, porque a maior parte dos agricultores pesquisados não tem o hábito de anotar as despesas e receitas durante todo o ano, o que faz com que o agricultor responda com mais exatidão os custos e receitas mensais. Terceiro, a olericultura tem ciclo curto e os dados mensais são facilmente captados. O objetivo do trabalho anterior foi estudar o sistema e não as culturas separadamente.

No presente estudo, os dados econômicos mensais foram utilizados com o modelo da Demonstração de Resultados do Exercício (DRE). A DRE é um demonstrativo contábil que apresenta as operações da empresa durante o exercício social, com função de designar as causas das variações patrimoniais (ABRANTES, 1998), apresentando de forma ordenada todas as contas de resultado, das receitas operacionais até o lucro líquido do exercício. A finalidade de um demonstrativo de resultados na agricultura orgânica foi fornecer uma visão global sobre as atividades e os resultados financeiros decorrentes. Os dados coletados foram inicialmente organizados para que fosse obtido o Resultado Líquido (RL). As equações apresentadas no Quadro 1 definem os termos empregados e desdobram os seus componentes.

O atual trabalho utilizou técnicas de análise estatística descritiva, de correlação e de regressão linear. Com a estatística descritiva foram utilizadas médias, medianas e desvios padrões das variáveis sob estudo. Também foram usadas as amplitudes, variação entre os dados mínimos e os máximos da amostra. Estruturaram-se gráficos e tabelas com as distribuições das variáveis categóricas e das variáveis discretas agrupadas em intervalos. Com auxilio da análise de comparação de médias estabeleceram-se os comportamentos de diversos fatores relevantes. Já para a análise de correlação e regressão linear múltipla estabeleceram-se relações entre os fatores em estudo e o resultado líquido (RL) das propriedades orgânicas. Foram utilizados os gráficos de dispersão e os coeficientes de correlação de Pearson para medir se existe associação e quanto é sua força de associação entre duas variáveis. (SMAILES; McGRANE, 2002, p. 117). 
Quadro 1 - Variáveis estimadas

\begin{tabular}{|l|l|l|}
\hline Equação 1 & RL = VBPA - DespT & $\begin{array}{l}\text { Resultado Líquido (RL) é igual ao Valor Bru- } \\
\text { to da Produção Agropecuária (VBPA) menos } \\
\text { as Despesas Totais (DespT). }\end{array}$ \\
\hline Equação 2 & VBPA = VPA + VPP & $\begin{array}{l}\text { (VBPA) são as somas das vendas de produ- } \\
\text { tos agrícolas (VPA) mais as vendas da pro- } \\
\text { dução pecuária (VPP). }\end{array}$ \\
\hline Equação 3 & $\begin{array}{l}\text { DespT }=\text { Depr }+ \text { ArImp } \\
+ \text { MdoC + ProL + CI }\end{array}$ & $\begin{array}{l}\text { As despesas totais (DespT) são um conjunto } \\
\text { formado por: depreciação (Depr); arrenda- } \\
\text { mentos e impostos (ArImp); despesas de } \\
\text { Mão-de-obra contratada (MdoC); pró-labore } \\
\text { (ProL); consumo intermediário (CI). }\end{array}$ \\
\hline Equação 4 & $\begin{array}{l}\text { CI }=\text { GI + AlugMáq }+ \\
\text { Transp + ALT + ODesp }\end{array}$ & $\begin{array}{l}\text { O consumo intermediário (CI) é resultado } \\
\text { da soma das variáveis: gasto de insumos } \\
\text { (GI); aluguel de máquinas (AlugMáq); des- } \\
\text { pesas de transporte (Trasnp); água, luz, tele- } \\
\text { fone (ALT); outras despesas (ODesp). }\end{array}$ \\
\hline
\end{tabular}

\section{Observações:}

a) A depreciação é o valor mensal da perda do valor do capital fixo imobilizado na propriedade. É um valor contábil para compensar o desgaste dos bens. Não é incluído o valor da terra, porque este item não sofre depreciação. O cálculo é realizado com os mesmos parâmetros de Darolt (2000), feito pelo método linear, descontando do valor do bem $15 \%$ de valor sucata (valor residual) e dividindo-se por 300 meses de vida útil para as benfeitorias e instalações ou dividindo-se por 120 meses para as máquinas, equipamentos e veículos. Segundo esse autor, o valor de sucata e a vida útil são estimados com base em Guerreiro (1997).

b) O pró-labore é o valor correspondente ao trabalho dos proprietários e seus familiares dedicados à atividade agrícola. Este valor não é vinculado ao gasto da família. Enquanto que, os gastos da família são as efetivas retiradas e pagamentos pessoais dos agricultores, independente da atividade produtiva, o pró-labore é o calculo da remuneração do serviço prestado à produção. Referindo-se a essa remuneração, Lima (1995, p. 53) comenta que: "no caso da agricultura familiar, o indicador normalmente utilizado é o custo de oportunidade do trabalho, medido através do salário mínimo regional por unidade de trabalho”. Nesse estudo, o valor utilizado do pró-labore é obtido pela multiplicação do equivalente homem (HE) da família utilizado na agricultura pelo valor do salário mínimo vigente na época, que correspondia a R \$130,00/mês.

c) O gasto da família e as rendas não agrícolas ficam fora dos cálculos. Essa atitude é fundamental para analisar apenas os fatores envolvidos diretamente com a produção agrícola, isolando as necessidades dos produtores e suas receitas não vinculadas às atividades produtivas.

d) A coleta das informações não priorizava uma avaliação rigorosa do valor da terra. As variações dos valores atribuídos pelos próprios agricultores chegam a oscilar cinqüenta vezes, entre a menor e a maior valorização do hectare. Desta forma, não foi optado pela utilização do custo de oportunidade da terra, pois este indicador produziria falha nos resultados. 


\section{Resultados e discussão \\ Características do Produtor Orgânico}

\subsection{Características das Famílias}

O agricultor responsável pela atividade agrícola tem sua idade distribuída de forma muito semelhante nos dois grupos estudados, apresentando uma média de 39,5 anos para os produtores em conversão e 40,3 anos para os certificados. O número de filhos é reduzido e quase semelhante para os dois conjuntos, onde os agricultores em conversão tem média de 2,0 filhos por família e os certificados com média de 2,2 filhos por família. Embora o tamanho da família seja um fator importante no estudo da agricultura orgânica, neste caso, não representa uma característica diferenciadora dos grupos. As médias são muito próximas, 4,3 pessoas por família para os produtores em certificação e 4,5 pessoas por família para os certificados.

\subsection{Escolaridade e Atividades Anteriores}

O conjunto total dos 57 agricultores orgânicos (57AO) possui uma polaridade na distribuição da escolaridade, devido a uma disparidade que ocorre entre a escolaridade dos dois grupos. Enquanto que entre os agricultores em conversão (20EC) $40 \%$ cursaram até a $4^{\text {a }}$ série e apenas $15 \%$ o nível superior, entre os agricultores certificados (37AC) apenas $27 \%$ cursaram até a $4^{\text {a }}$ série e $46 \%$ o nível superior, conforme Figura 2.

Figura 2 - Escolaridade - Separando o Fator Certificação

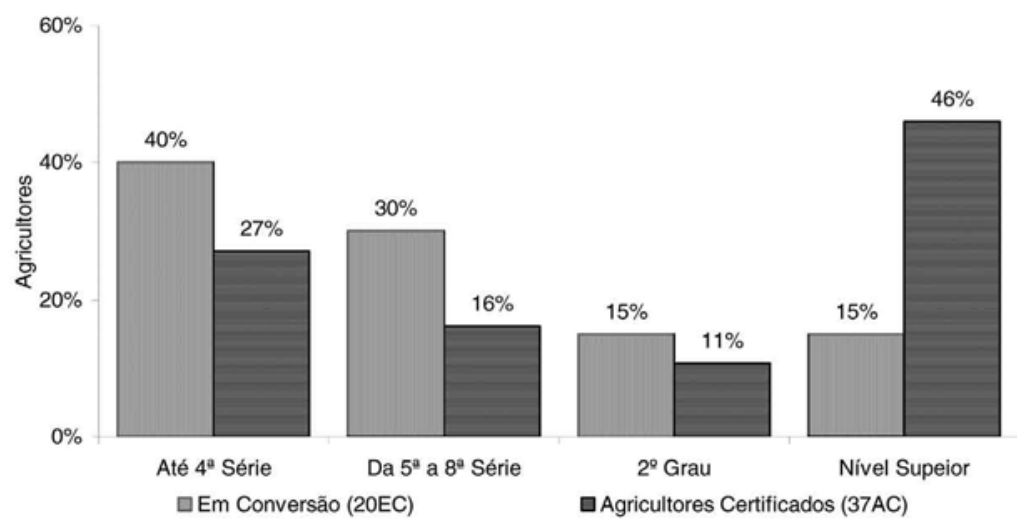

Fonte: Elaborado pelos autores, baseado nos dados fornecidos por Darolt. (2000) 
Se a educação formal é um grande diferencial quando separamos a amostra pelo fator certificação, na experiência profissional teremos um reforço nesta diferenciação. Uma peculiaridade dos agricultores orgânicos da RMC é que $56 \%$ deles já desenvolveram outras atividades não agrícolas. Esta média é influenciada pelo grupo em conversão, com pouca experiência no comércio ou serviços (apenas um terço nesta situação). Já entre os agricultores certificados, dois terços deles apresentam vivência em outras áreas, conforme Tabela 2.

Tabela 2 - Atividades Anteriores - Separando o Fator Certificação

\begin{tabular}{l|l|l|l|l}
\hline Grupos & Experiência & Percentual & Atividades & $N^{\circ}$ Produtores \\
\hline \multirow{3}{*}{ Em Conversão } & Só agricultura & $65 \%$ & Agricultura & 13 \\
\cline { 2 - 5 } & Outras & \multirow{2}{*}{$35 \%$} & Comércio & 1 \\
\cline { 3 - 5 } & & Serviços & 6 \\
\hline \multirow{2}{*}{$\begin{array}{l}\text { Agricultor Certi- } \\
\text { ficado }\end{array}$} & Só agricultura & $32 \%$ & Agricultura & 12 \\
\cline { 2 - 5 } & Outras & \multirow{2}{*}{$68 \%$} & Comércio & 4 \\
\cline { 3 - 5 } & & Serviços & 21 \\
\hline
\end{tabular}

Fonte: Elaborado pelos autores, baseado nos dados fornecidos por Darolt. (2000)

Observam-se aqui dois fatores marcantes para superar a difícil etapa de conversão para a agricultura orgânica. O nível de escolaridade e a experiência com outras atividades profissionais são ingredientes importantes para desencadear o processo de transformação. Certamente não são condições indispensáveis, pois agricultores com baixa escolaridade e vivência apenas com a agricultura conseguem certificação e se colocaram positivamente no mercado. Entretanto, produtores com capacitação formal e conhecimento de mercado desempenham um papel de trazer novas visões e quebrar antigos paradigmas, promovendo um efeito de multiplicação das práticas orgânicas.

\subsection{Avaliação da Mão-de-obra}

O Equivalente Homem (EH) Total da Família tem a mesma média de 3,1 EH para os dois conjuntos e praticamente a mesma distribuição, como informa a Tabela 3. Quanto ao EH Utilizado da Família na produção, as médias variam pouco e oscilam de 1,9 EH para os agricultores 
em certificação para 1,8 EH para os certificados. Verifica-se uma forte dedicação dos membros das famílias dos dois grupos a outras atividades não agropecuárias.

Tabela 3 - Equivalente Homem (EH) - Separando o Fator Certificação

\begin{tabular}{l|l|l|l|l|l|l|l|l}
\hline \multicolumn{2}{l|}{ EH Familiar Total } & \multicolumn{3}{l|}{ EH Familiar Utilizado } & \multicolumn{3}{l}{ EH Contratado } \\
\hline Grupos & $20 \mathrm{EC}$ & $37 \mathrm{AC}$ & Grupos & $20 \mathrm{EC}$ & $37 \mathrm{AC}$ & Grupos & $20 \mathrm{EC}$ & $37 \mathrm{AC}$ \\
\hline Sem $\mathrm{EH}$ & $0 \%$ & $0 \%$ & Sem $\mathrm{EH}$ & $0 \%$ & $3 \%$ & Sem $\mathrm{EH}$ & $50 \%$ & $19 \%$ \\
\hline Até $1 \mathrm{EH}$ & $10 \%$ & $8 \%$ & Até $1 \mathrm{EH}$ & $25 \%$ & $35 \%$ & Até $1 \mathrm{EH}$ & $30 \%$ & $38 \%$ \\
\hline$>1$ até 2 & $20 \%$ & $27 \%$ & $>1$ até 2 & $40 \%$ & $32 \%$ & $>1$ até 2 & $15 \%$ & $16 \%$ \\
\hline$>2$ até 3 & $25 \%$ & $24 \%$ & $>2$ até 3 & $25 \%$ & $19 \%$ & $>2$ até 3 & $0 \%$ & $3 \%$ \\
\hline$>3$ até 4 & $30 \%$ & $24 \%$ & $>3$ até 4 & $10 \%$ & $8 \%$ & $>3$ até 4 & $0 \%$ & $5 \%$ \\
\hline$>4$ até 8 & $15 \%$ & $16 \%$ & $>4$ até 6 & $0 \%$ & $3 \%$ & $>4$ até 14 & $5 \%$ & $19 \%$ \\
\hline Média $=$ & $3,1 \mathrm{EH}$ & $3,1 \mathrm{EH}$ & Média $=$ & $1,9 \mathrm{EH}$ & $1,8 \mathrm{EH}$ & Média $=$ & $0,7 \mathrm{EH}$ & $2,1 \mathrm{EH}$ \\
\hline
\end{tabular}

Fonte: Elaborado pelos autores, baseado nos dados fornecidos por Darolt. (2000)

A grande diferença na analise da questão da força de trabalho agrícola, em relação à certificação, é a mão-de-obra contratada. O EH Contratado dos produtores em conversão é muito reduzido, $50 \%$ das propriedades não contratam serviços externos, resultando uma pequena média de 0,7 EH Contratado para as propriedades sem certificação, conforme mostra a Tabela 3. De forma diversa, $81 \%$ dos produtores certificados contratam mão-de-obra, numa média de 2,1 EH por propriedade. Como o total de mão-de-obra envolvida, EH Total, é a soma do EH Utilizado da Família mais o EH Contratado, desta forma, se mantém a diferença entre os grupos de produtores orgânicos. A distribuição de frequiências dos agricultores em conversão está centrada na média de 2,7 EH, como mostra a Figura 3, enquanto que a amostra dos agricultores certificados está distribuída com base em uma média de 3,9 EH Total. 
Figura 3 - Equivalente-Homem Total - Separando o Fator Certificação

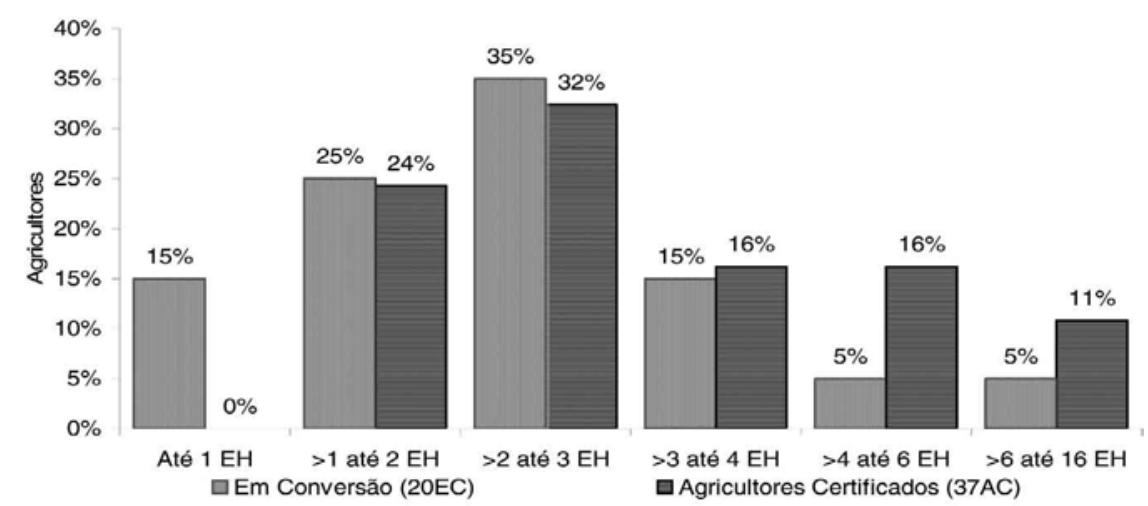

Fonte: Elaborado pelos autores, baseado nos dados fornecidos por Darolt. (2000)

\subsection{Análise das Características Técnico-Agronômicas}

A prática conservacionista de adubação verde e cobertura morta do solo é significativamente superior para os agricultores certificados, realizando esta prática em $97 \%$ dos estabelecimentos, contra $75 \%$ dos produtores que não tem certificação. O nível de degradação é mais intenso nos produtores em conversão. O uso de equipamentos de preparo do solo que aumentem a eficiência da mão-de-obra é fator que destaca as diferenças dos grupos. Enquanto os agricultores em conversão apenas 10\% possuem tração mecânica com uso de enxada rotativa, os certificados utilizam esta ferramenta em $73 \%$ das propriedades. Outro fator de destaque, que será abordado na análise de regressão linear múltipla mais adiante, é o investimento para produzir com auxilio da tecnologia de manejo de estufa. Se por um lado, os agricultores em conversão apenas $20 \%$ conseguem fazer uso desta técnica, mais do dobro, $43 \%$ dos agricultores certificados conseguem utilizar os benefícios do manejo de estufa, ampliando a produção e o período produtivo, conseguindo obter preços melhores.

\subsection{Biodiversidade e Número de Espécies Cultivadas}

A rotação de culturas é praticada na mesma intensidade pelos dois grupos de agricultores, em torno de $95 \%$ dos casos. O plantio consorcia- 
do é pouco mais intenso nos agricultores certificados, $41 \%$, contra $25 \%$ dos em conversão, porém, estatisticamente não são significativamente diferentes. O sistema de diversificação apresenta superioridade significativa para os produtores certificados. Os agricultores em conversão tem em média 9 espécies cultivadas, enquanto que os agricultores certificados utilizam em média 11 espécies em suas atividades. A busca da diversidade depende muito de uma conquista técnica, administrativa e comercial, onde o maior número de espécies representa, até um certo limite, estabilidade do processo produtivo. Existe a busca do número ideal de espécies cultivadas entre: a diversidade técnica, que preconiza um grande número de espécies; o ideal administrativo, onde a monocultura é o mais prático para gerenciar; e o ideal comercial, que centra a atenção em poucas oportunidades mais lucrativas. Desta forma, os produtores em conversão ainda devem conquistar patamares de maior diversidade.

\subsection{Análise de Indicadores Financeiros}

Os valores foram coletados em reais no ano da pesquisa e são abordados através da indexação com o salário mínimo (SM) da época, que era de R \$130,00. Como não foi possível obter as informações de todos os agricultores selecionados, serão avaliados apenas 35 dos 37 agricultores certificados. Considerando a existência de um pequeno número de produtores que obtém receitas muito elevadas em relação à maioria, neste conjunto de indicadores serão usadas as medianas para representar a tendência central.

A análise do valor bruto da produção agropecuária (VBPA), que representa a produção total sem nenhum desconto, apresenta uma grande discrepância quando estudados os grupos separados pelo fator certificação. Uma receita bruta agropecuária superior a $6 \mathrm{SM} / \mathrm{mês}$ é atingida apenas por $20 \%$ das propriedades em conversão estudadas, enquanto que $71 \%$ dos agricultores certificados conseguem faturamento superior. Outra comparação é que faturamentos de mais de $12 \mathrm{SM} /$ mês são alcançados por apenas 10\% dos agricultores em conversão contra 46\% dos certificados, como pode ser visto na Figura 4. As medianas também demonstram essa marcante diferença, pois os produtores em conversão tem mediana de $2,7 \mathrm{SM}$ /mês e os certificados têm de $11,5 \mathrm{SM} / \mathrm{mês}$. 
Figura 4 - Valor Bruto da Produção Agropecuária Separando o Fator Certificação

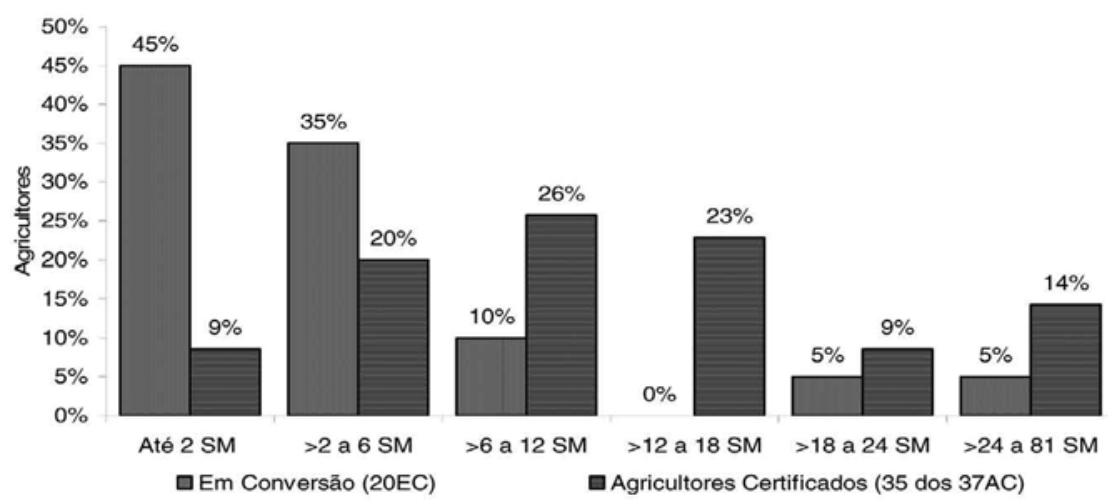

Fonte: Elaborado pelos autores, baseado nos dados fornecidos por Darolt. (2000)

O resultado líquido (RL) é obtido do VBPA subtraindo-se as despesas totais. $\mathrm{O}$ que se observa é um grupo que não consegue resultado positivo, chegando a $85 \%$ dos produtores em conversão e $37 \%$ dos certificados que não conseguem uma RL maior que zero. Uma grande diferença é que apenas $10 \%$ dos agricultores em conversão conseguem resultado líquido superior a $1 \mathrm{SM} /$ mês, contra $63 \%$ dos certificados que conseguem lucratividade acima desse valor, conforme a Tabela 4. É importante destacar que $43 \%$ dos produtores certificados conseguem RL superior a $4 \mathrm{SM} / \mathrm{mês}$, demonstrando uma capacidade econômica importante, contrastando com apenas $5 \%$ dos produtores em conversão.

Tabela 4 - Resultado Líquido - Separando o Fator Certificação

\begin{tabular}{|c|c|c|c|c|}
\hline \multirow{2}{*}{$\begin{array}{l}\text { Classes de Valores Salário } \\
\text { Mínimo / mês }\end{array}$} & \multicolumn{4}{|c|}{ Resultado Líquido - RL } \\
\hline & 20EC & Acumulado & 35 dos $37 \mathrm{AC}$ & Acumulado \\
\hline Zero ou Negativo & $85 \%$ & $85 \%$ & $37 \%$ & $37 \%$ \\
\hline Até $1 \mathrm{SM} / \mathrm{mês}$ & $5 \%$ & $90 \%$ & $0 \%$ & $37 \%$ \\
\hline$>1$ a 4 SM/mês & $5 \%$ & $95 \%$ & $20 \%$ & $57 \%$ \\
\hline$>4$ a $8 \mathrm{SM} / \mathrm{mês}$ & $0 \%$ & $95 \%$ & $28 \%$ & $85 \%$ \\
\hline$>8$ a $12 \mathrm{SM} / \mathrm{mês}$ & $0 \%$ & $95 \%$ & $6 \%$ & $91 \%$ \\
\hline > 12 a $41 \mathrm{SM} / \mathrm{mês}$ & $5 \%$ & $100 \%$ & $9 \%$ & $100 \%$ \\
\hline
\end{tabular}

Fonte: Elaborado pelos autores, baseado nos dados fornecidos por Darolt. (2000) 


\subsection{Análise das Despesas Totais em Relação ao Resultado Líquido}

Há uma grande diversidade de situações entre os agricultores orgânicos da RMC, quando analisado o aspecto econômico. As despesas totais refletem o conjunto de fatores que interferem no valor bruto da produção agropecuária e, portanto, no resultado líquido. As despesas totais conseguem convergir para si todos os resultados do processo produtivo, expressando em valor monetário as diversas ações que foram realizadas pelos agricultores. As despesas aqui relacionadas são despesas contábeis e administrativas, não necessariamente o produtor tem que desembolsar esses valores mensalmente, como são os casos da depreciação e do pró-labore 4 . A Figura 5 mostra os dois grupos de agricultores, apresentando de forma crescente, da esquerda para a direita, os resultados líquidos, iniciando com os resultados negativos, prejuízos, e terminando com os maiores positivos, os lucros. Esta seqüência é mantida para as próximas quatro figuras.

Figura 5 - Resultado Líquido - RL - (R\$ / mês)

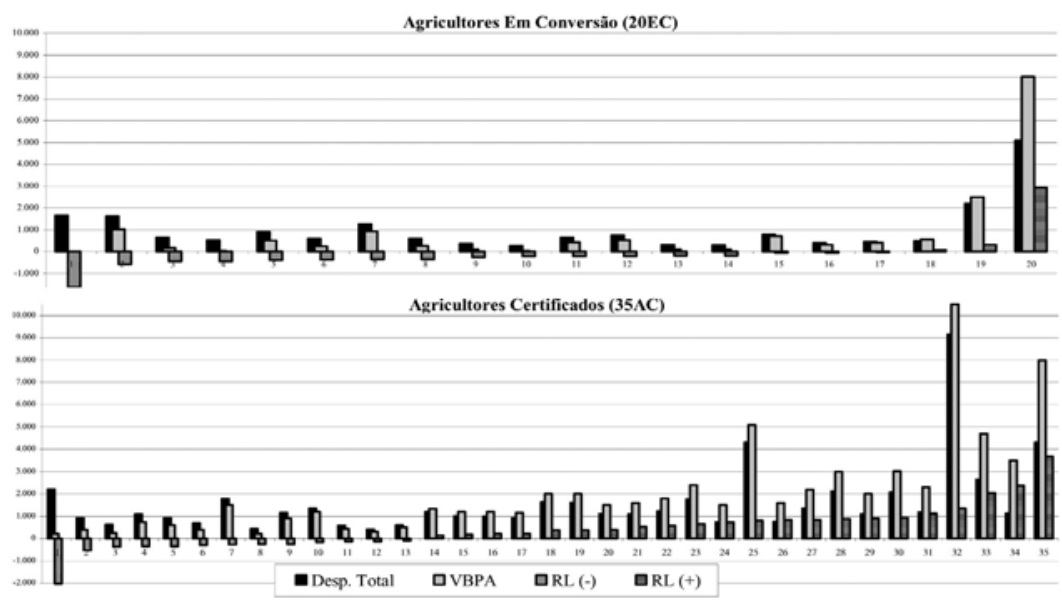

Fonte: Elaborado pelos autores, baseado nos dados fornecidos por Darolt. (2000)

${ }^{4}$ As Figuras 5 a 9 querem mostrar a grande variação da composição das despesas entre os agricultores analisados, não desejando serem conclusivas. Os gráficos são usados para uma visualização das diferenças das despesas em relação ao resultado líquido crescente. A variação da composição das despesas não consegue ser observada quando usados gráficos com médias, medianas ou distribuição de freqüências. 
Na agricultura química convencional o consumo intermediário (CI) é de importância muito grande nos custos totais, havendo uma relação direta entre ambas as variáveis. O consumo intermediário $(\mathrm{CI})$, por sua vez, é muito dependente do gasto de insumos (GI), de uma forma muito constante e linear. Um aspecto deve ser destacado no grupo de agricultores orgânicos: a composição das despesas totais é muito variada, como pode ser observado nas Figuras 6 e 7 . A amplitude é muito grande para todos os fatores.

Existem muitos estabelecimentos que não possuem despesa de mão-de-obra contratada; em outros, o envolvimento do trabalho direto dos proprietários é mínimo; em outras situações é grande o uso de mão-de-obra. Observando o total de despesa envolvendo o trabalho, isto é, somando a mão-de-obra contratada e o pró-labore, a amplitude é imensa: a variação é de $25 \%$ até $71 \%$ das despesas no grupo em conversão (20EC); e oscilando entre $24 \%$ e $76 \%$ nos agricultores certificados (35AC). Este fato indica que existem dois extremos: propriedades familiares intensivas em mão-de-obra familiar e propriedades administradas de forma empresarial, com menor envolvimento dos membros da família. Nestas últimas, ocorre um maciço envolvimento com insumos e tecnologias, como mecanização e equipamentos para ampliar a produção, com potencial de rendimentos elevados.

Figura 6 - Composição das Despesas Totais em Reais (R\$ / mês)

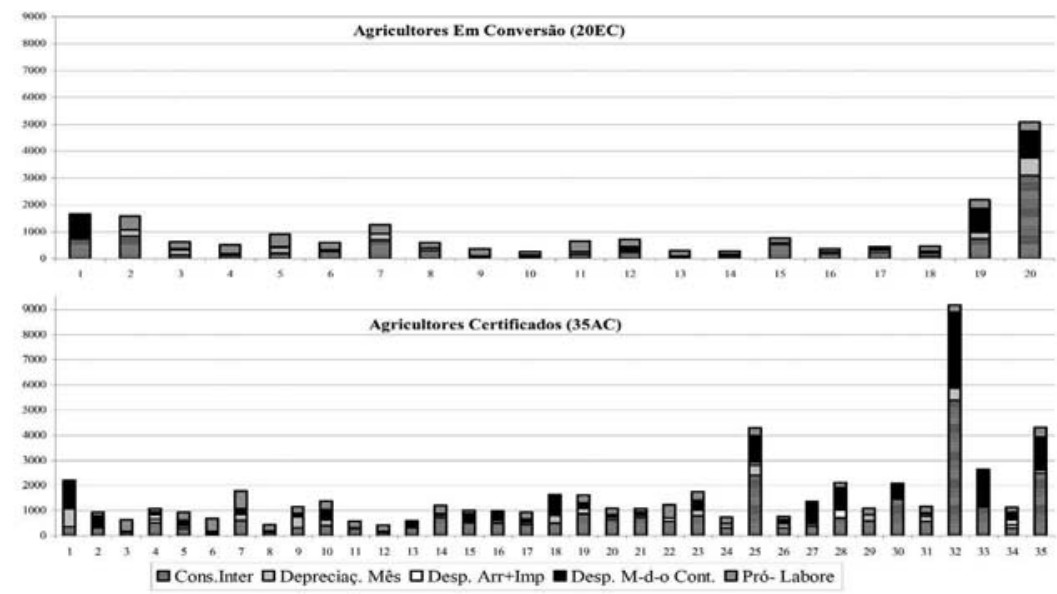

Fonte: Elaborado pelos autores, baseado nos dados fornecidos por Darolt. (2000) 
Figura 7 - Composição Percentual das Despesas Totais (\%)
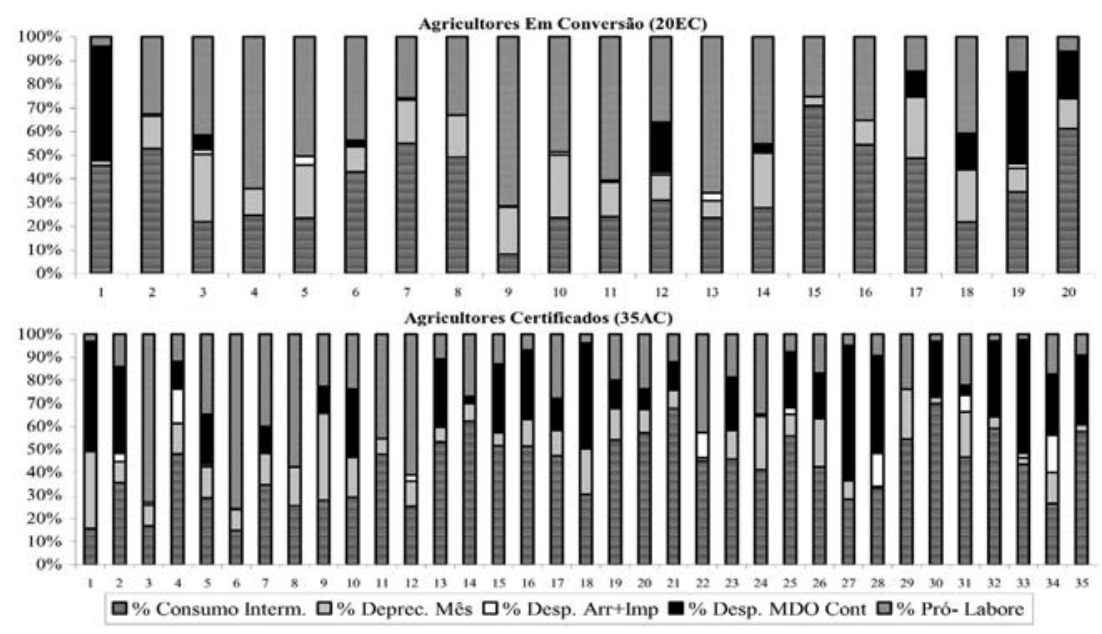

Fonte: Elaborado pelos autores, baseado nos dados fornecidos por Darolt. (2000)

Outro ponto de destaque é a depreciação mensal, item que reflete o volume de capital fixo imobilizado pelo produtor. A despesa com depreciação é de 2 a $28 \%$ para os agricultores em conversão e 1 a $38 \%$ para os já certificados. Este item mostra uma grande diferença entre os agricultores orgânicos em relação ao volume total de capital fixo investido. Para a agricultura orgânica não bastam investimentos elevados, às vezes inapropriados, para conseguir resultados positivos. Certamente é o equilíbrio entre as atividades e investimentos que podem proporcionar melhor rentabilidade.

A variação do consumo intermediário, que é um dos principais itens da despesa total, continua mostrando forte oscilação. O consumo intermediário participa com uma distribuição entre 8 a $71 \%$ para os agricultores em conversão e entre 15 e $70 \%$ para os certificados. Isto reflete uma ampla gama de processos produtivos utilizados. Variando desde sistemas produtivos que praticamente não possuem dependência de entrada de insumos ou outros serviços externos, até processos de produção que estão totalmente vinculados aos limites exteriores da fazenda.

Altmann e Oltramari (2004) constataram que entre os produtores orgânicos da Grande Florianópolis aqueles com olericultura como principal fonte de renda apresentam menor taxa de consumo interno e, 
conseqüentemente, maior taxa de valor agregado que seus produtores espelhos da agricultura química convencional. Cada trabalhador na horticultura orgânica gera um valor agregado de $\mathrm{R} \$ 19.814,00$ por ano, $75,4 \%$ superior ao trabalhador convencional. Idêntico resultado é observado em relação ao valor agregado por hectare. Dois fatores são apontados: redução nos gastos com insumos e a obtenção de melhores preços para os produtos orgânicos.

A composição do consumo intermediário já foi demonstrada na Equação 4, entretanto, a fórmula não pode avaliar a maneira como ela é distribuída pelos grupos em estudo. Conforme mostram as Figuras 8 e 9, o consumo intermediário é muito variável dentro de sua própria constituição. O gasto de insumos possui oscilação grande, mesmo representando em média mais da metade do consumo intermediário. O percentual de gasto de insumos não demonstra, neste estudo de caso, nenhuma correlação significativa com o resultado líquido, significando que muitos processos produtivos podem ser desenvolvidos, com maior ou menor utilização de insumos externos, obtendo bom desempenho econômico.

Figura 8 - Composição do Consumo Intermediário em Reais (R\$ / mês)

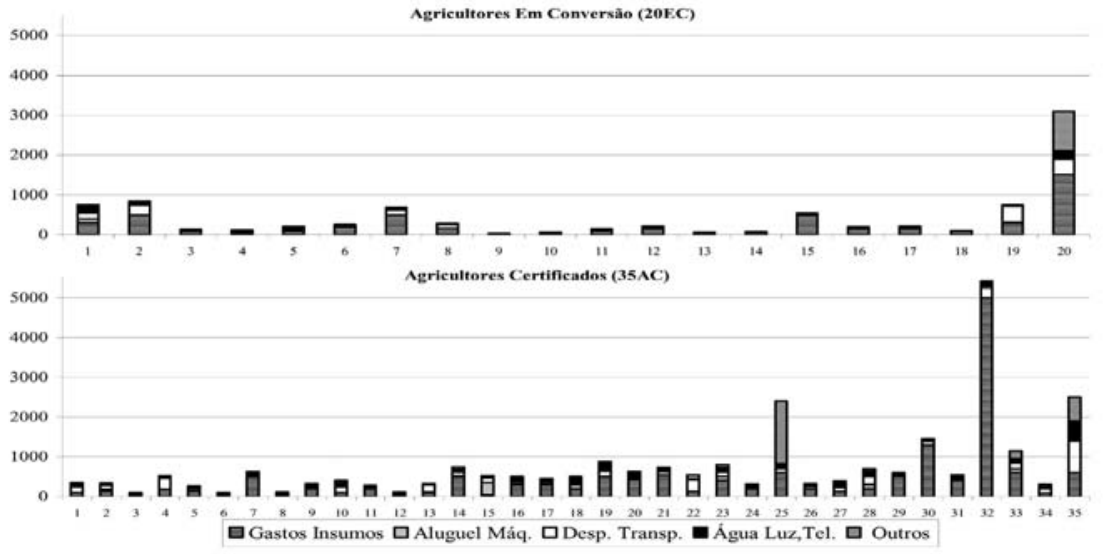

Fonte: Elaborado pelos autores, baseado nos dados fornecidos por Darolt. (2000) 
Figura 9 - Composição Percentual do Consumo Intermediário
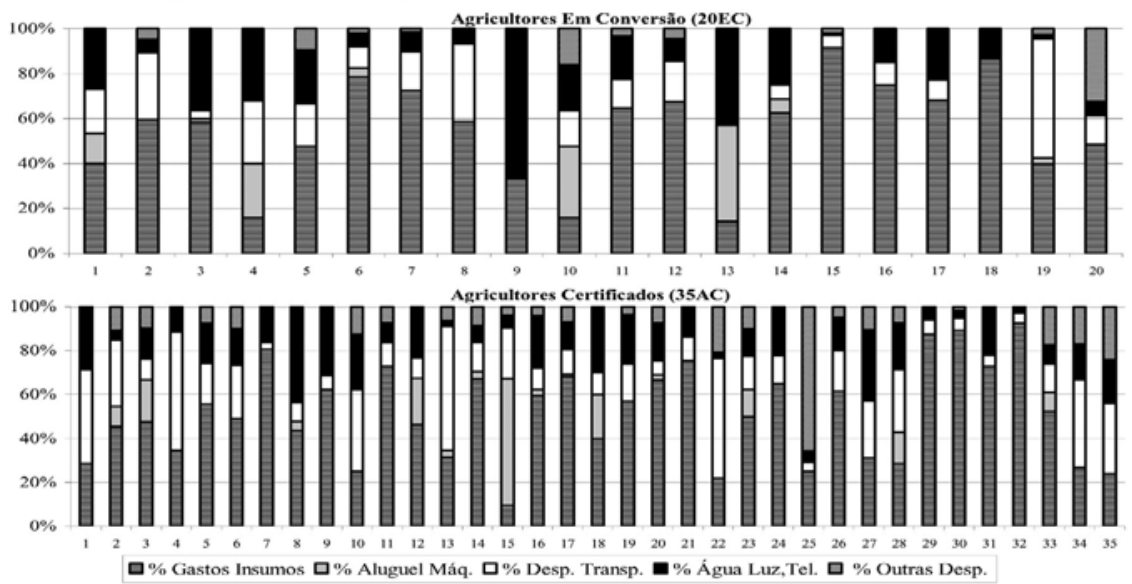

Fonte: Elaborado pelos autores, baseado nos dados fornecidos por Darolt. (2000)

\subsection{Análise de Regressão Linear Múltipla em Relação ao Resultado Líquido}

A agricultura orgânica tem características muito distintas da agricultura química convencional. Desta forma, é importante analisar cada caso concreto e avaliar quais são os fatores que mais interferem na obtenção de resultado líquido positivo para o agricultor orgânico. O capital fixo (CF) e a superfície agrícola útil (SAU) são dois fatores importantes para estudar a relação com o resultado líquido. Entretanto, para este grupo de agricultores, conforme os gráficos de dispersão da Figura 10 e os coeficientes de correlação de Pearson, não foi observada relação estatística entre essas variáveis e o resultado líquido. Um terceiro indicador foi experimentado, o coeficiente obtido pela divisão do capital fixo pela superfície agrícola útil (CF/SAU), que indica o grau de investimento por unidade de área. Mesmo assim, o valor do capital fixo por hectare $(\mathrm{R} \$ /$ ha) também não permite observar correlação com o resultado líquido. 
Figura 10 - Correlações da RL(R\$) com CF(R\$), SAU(ha) e CF/SAU(R $\$ / h a)$
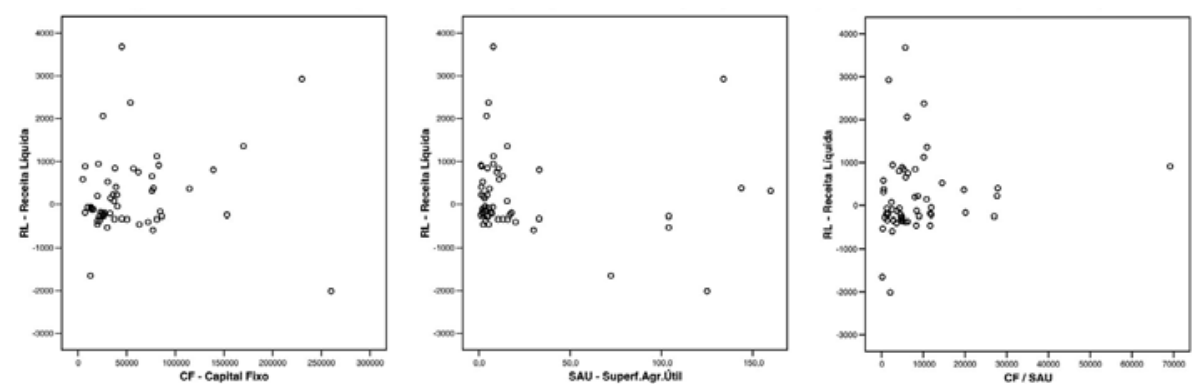

Fonte: Elaborado pelos autores, baseado nos dados fornecidos por Darolt. (2000)

O objetivo deste trabalho é analisar que variáveis são importantes para responder os diferentes resultados líquidos obtidos neste conjunto de agricultores. Não se tem pretensão de desenvolver uma função abrangente e capaz de, ao sair dos limites desta amostra, permanecer válida. Pretende-se destacar as variáveis econômicas e técnicas que fortemente influenciam na geração de riqueza líquida para o produtor orgânico. Para isso, foram utilizadas variáveis qualitativas, trazendo, de certa forma, subjetividade e menor precisão ao modelo de regressão. Não se busca necessariamente a precisão da utilização da equação para projetar futuros resultados. Salienta-se que isso não compromete o objetivo deste estudo. O que é relevante é a identificação dos fatores mais marcantes dessa realidade.

Embora a regressão não incorpore todos os fatores que influenciam no resultado líquido, destaca os mais marcantes. Muitos fatores que contribuem positiva ou negativamente para o resultado da atividade agrícola orgânica não são incluídos no modelo, por terem correlação com as variáveis independentes selecionadas. A perda com a exclusão dessas variáveis menos relevantes é compensada pela visualização dos fatores que merecem maior destaque e que trazem consigo parte da explicação que as variáveis excluídas mostrariam. A regressão permite indicar uma quantificação da importância dessas variáveis principais, de forma multivariada, ou seja, a contribuição de cada variável na presença das demais. A quantificação é expressa através dos coeficientes de regressão estimados pelo modelo. 
As variáveis do banco de dados dos agricultores orgânicos são avaliadas pelas suas relações com o resultado líquido, utilizando as correlações de Pearson significativas a $5 \%$. Em seguida, essas variáveis são empregadas no programa estatístico SPSS, no módulo de análise de regressão linear. Com o auxílio do método Backward são selecionadas as variáveis independentes com maior poder de explicação. Com isso é obtido o modelo de regressão linear múltiplo que indica quais fatores contribuem para o sistema produtivo orgânico em estudo ${ }^{5}$. A análise aponta para a seguinte função:

\section{Resultado Líquido $=$ f $($ Cert, GF, MdoT, ME, IA) $\quad$ Equação 5}

- Cert $=$ Certificação $(0=$ não possui; $1=$ possui $)$;

- $\mathbf{G F}=$ Gastos da Família (R\$);

- MdoT = Mão-de-obra Total (Equivalente Homem / mês);

- $\mathbf{M E}=$ Manejo de Estufa ( $0=$ não possui; $1=$ possui);

- IA = Integração das Atividades ( 0 = ausência; 1 = pouca; 2 = média; $3=$ completa).

Todas as informações são referentes a dados mensais. Após submeter ao programa SPSS, são obtidos os seguintes parâmetros:

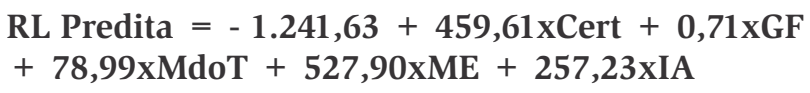

\section{Equação 6}

O modelo ajustado possui um grau de explicação de $52 \%$ da variabilidade dos dados $\left(\mathrm{R}^{2}=0,526\right)$. A reta de regressão é confirmada pelo teste de ANOVA ( $F=10,447$, F de Significação < 0,001), conforme Figura 11. O teste de Durbin-Watson $(1,81)$ indica que a regressão linear múltipla não tem auto-correlação, bem como os coeficientes VIF $(1,09$ a 1,20) demonstram não existir problema de multicolinearidade, ou seja, não existe associação entre as variáveis independentes. Do grupo de 55 produtores orgânicos analisados estatisticamente na regressão linear múltipla, dois

5 O uso do logaritmo para a variável dependente reduziria muito o número de agricultores da amostra, devido à grande ocorrência de Resultado Líquido negativo. Desta forma, optou-se pelo modelo linear com os números originais. 
agricultores foram retirados por serem outliers, valores extremos que influenciam os resultados, um com resultado líquido muito elevado e outro muito inferior para suas características dentro do conjunto.

Figura 11 - Dados Estatísticos da Regressão Linear Múltipla

\begin{tabular}{|c|c|c|c|c|c|c|c|}
\hline \multicolumn{4}{|c|}{ Estatistica Descritiva } & \multirow[t]{2}{*}{ 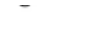 } & & & \\
\hline & Média & Desvio Padrão & $\bar{N}$ & & & & \\
\hline RL - Receita Liquida & 214,51 & 834,527 & 53 & & & & \\
\hline Certificação & 0,64 & 0,484 & 53 & & & & \\
\hline Gastos Familia & 463,40 & 313,749 & 53 & & & & \\
\hline Manejo Estufa & 0,36 & 0,484 & 53 & & & & \\
\hline Mdo Total & 3,33 & 2,4728 & 53 & & & & \\
\hline Integraçăo Atividades & 1.47 & 0,775 & 53 & & & & \\
\hline \multicolumn{8}{|c|}{ Estatistica de regressảo } \\
\hline R múltiplo & 0,726 & & & & & & \\
\hline R-Quadrado & 0,526 & & & & & & \\
\hline R-quadrado ajustado & 0,476 & & & & & & \\
\hline Erro padrāo & 604,101 & & & & & & \\
\hline Observaçōes & 53 & & & & & & \\
\hline Durbin-Watson & 1,811 & & & & & & \\
\hline \multicolumn{8}{|l|}{ ANOVA } \\
\hline & $g^{\prime}$ & $S Q$ & $M Q$ & $F$ & F de significação & & \\
\hline Regressão & 5 & 19062567,46 & 3812513,493 & 10,447 & 0,000 & & \\
\hline Residuo & 47 & 17152062,07 & 364937,491 & & & & \\
\hline \multirow[t]{2}{*}{ Total } & 52 & 36214629,53 & & & & & \\
\hline & Coeficientes & Emo padrāo & Statt & valor-P & $95 \%$ inferiores & $95 \%$ superiores & VIF \\
\hline Interseção & $-1,241,633$ & 238,669 & $-5,202$ & 0,000 & $-1721,773$ & $-761,493$ & \\
\hline Certificaçāo & 459,605 & 190,220 & 2,416 & 0,020 & 76,933 & 842,277 & 1,209 \\
\hline Gastos Familia & 0,713 & 0,288 & 2,479 & 0,017 & 0,134 & 1,292 & 1,160 \\
\hline Manejo Estufa & 527,899 & 181,088 & 2,915 & 0,005 & 163,596 & 892,201 & 1,095 \\
\hline Mdo Total & 78,994 & 36,235 & 2,180 & 0,034 & 6,099 & 151,890 & 1,144 \\
\hline Integraçāo Atividades & 257,227 & 111,979 & 2,297 & 0,026 & 31,954 & 482,500 & 1,072 \\
\hline
\end{tabular}

Fonte: Elaborado pelos autores, baseado nos dados fornecidos por Darolt. (2000)

Os gráficos de resíduos completam as análises para verificar a consistência e adequação do modelo, onde a distribuição dos resíduos é normal, com média zero e desvio padrão praticamente igual a um $(0,951)$, e a regressão dos resíduos padronizados mostram-se adequados a satisfazer aos pressupostos indispensáveis para um modelo de regressão linear múltipla. Ao aplicar a equação nos dados registrados dos agricultores, observa-se que existem muitas situações onde confirmam que o modelo está ajustado à realidade, conforme Figura 12. A seguir é analisado e interpretado o significado de cada variável independente e de seus coeficientes na função. 
Figura 12 - Resultado Líquido Previsto e Resultado Líquido Real

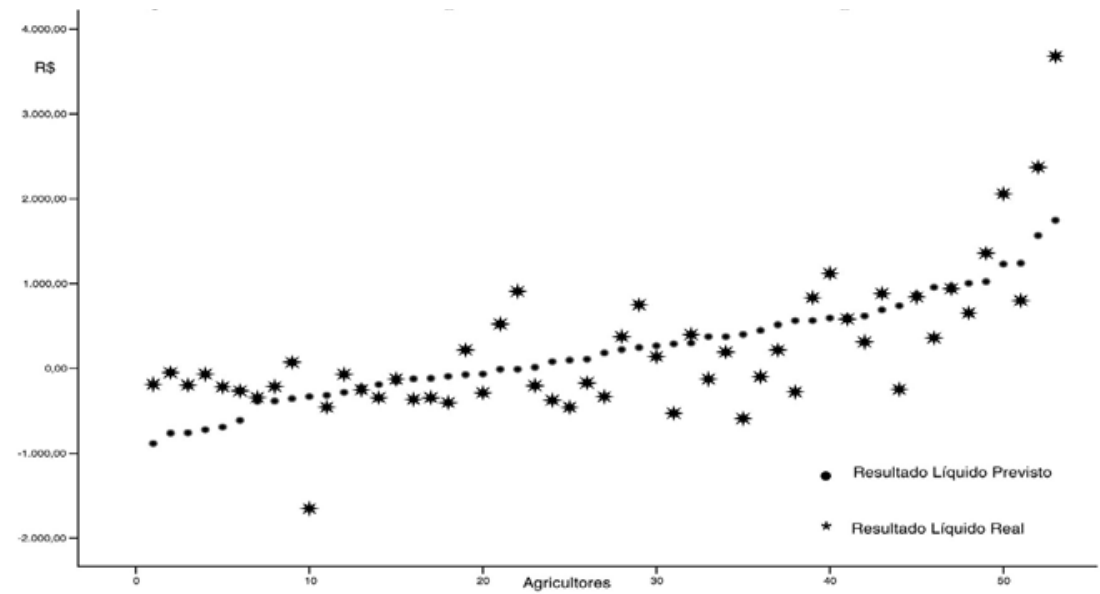

Fonte: Elaborado pelos autores, baseado nos dados fornecidos por Darolt. (2000)

A certificação é uma variável de controle, tipo dummy, é a característica que diferencia os dois grupos, indicando uma aptidão e qualificação dos agricultores perante o sistema produtivo orgânico. Seu efeito dentro do modelo confirma sua correlação direta com o resultado líquido, pois quem possui certificação, provavelmente, tem um resultado ampliado em $R \$ 459,60$ a mais que os agricultores não certificados. $O$ aumento do resultado líquido deve ser conseqüência de diversos fatores que a certificação induz no produtor: diminuição do custo pelo manejo mais adequado; aumento da eficiência do trabalho pela utilização de tecnologias mais apropriadas; incremento da produtividade quando o ecossistema atinge um patamar mínimo de harmonia, a resposta é a ocorrência de maiores produtividades; obtenção de maior preço de venda, pois conseguirá comercializar com o prêmio sobre o preço convencional, por ser certificado como orgânico.

Uma análise inicial concluiria que o gasto da família não é uma variável independente, ela seria justamente a variável que estaria na dependência do resultado líquido. Entretanto, estudos de agricultura com base no trabalho familiar, indicam que existe um balanço entre a utilização de sua força de trabalho e sua necessidade de consumo. Como a exploração econômica está parcialmente limitada pela força de trabalho apenas da família, a tendência de obter maiores receitas 
está vinculada às fadigas crescentes do cansaço do trabalho adicional (CHAYANOV, 1974). Isto é, se uma propriedade agrícola possui uma necessidade adicional de R $\$ 1,00$ por mês, usando o coeficiente do modelo, esse consumo adicional tenderá a explicar um resultado líquido maior em $\mathrm{R} \$ 0,71 /$ mês. Os gastos da família têm um peso considerável dentro da explicação da variável resultado líquido, pois esse coeficiente multiplica pelo valor dos gastos, que tem uma média de $\mathrm{R} \$ 463,40$. Desta forma, os gastos da família, em média, contribuem com $\mathrm{R} \$ 329,01$ por mês para explicar a variável resposta em questão.

A força total de trabalho também vem contribuir para o aumento do resultado líquido. Como a mão-de-obra é medida em equivalente homem (EH) por mês, isso significa que a cada contratação de mais um trabalhador, usando o coeficiente do modelo, se conseguirá obter um acréscimo de $\mathrm{R} \$ 78,99$ por mês. Cabe reforçar que esse modelo não tem o objetivo de previsões de extrapolação, simplesmente está explicando a importância que a mão-de-obra tem nesse estudo de caso. A força média da mão-de-obra total é de 3,3EH por propriedade, resultando uma contribuição média de R 260,67 por mês na explicação da variação do resultado líquido.

O manejo de estufas é uma variável que influencia muito o valor do resultado líquido. É introduzida no modelo como outra variável dummy, indicando um grau de maior qualificação tecnológica do produtor, pois, para grande maioria dos agricultores, a principal receita provém da olericultura. O conjunto de agricultores possui muitas práticas agrícolas que são fatores comuns a praticamente todos, como a rotação de cultura, adubação orgânica, entre outras. Esses manejos enquadram os produtores como orgânicos, porém não explicam as diferenças entre os resultados líquidos entre eles. Outras práticas agrícolas são desenvolvidas por um ou dois produtores, não ajudando a responder o fenômeno. O modelo escolhido contempla apenas dois fatores técnicos, o manejo de estufa e a integração das atividades, essa última será avaliada a seguir. Isto significa que o manejo de estufas é uma prática agrícola que auxilia decisivamente a obtenção de resultados positivos. Porém, para o agricultor usar essa tecnologia, precisa atingir um nível elevado de conhecimento e vivência de agricultura orgânica, bem como técnicas associadas para aumentar a eficiência do 
trabalho, da produtividade agrícola e da comercialização. A utilização do fator estufa, segundo seu coeficiente no modelo, pode possibilitar um acréscimo de $\mathrm{R} \$ 527,90$ por mês no resultado líquido do produtor orgânico do conjunto estudado.

Por fim, a integração das atividades é outro fator técnico que repercute positivamente no resultado líquido da produção orgânica. É uma variável ordinal e trabalhada em uma escala de zero $(0=$ ausência) a três $(3=$ completa), significando, respectivamente, a ausência ou a completa integração da propriedade com as produções agrícolas, pecuárias e florestais. São possíveis duas posições intermediárias: os estabelecimentos que tenham atingido um terço do padrão ideal recebem avaliação um $(1=$ pouca $)$; e os agricultores que alcançaram dois terços do preconizado recebem avaliação dois $(2=$ média $)$. A integração é um fator técnico e ambiental muito representativo para a atividade orgânica. É a síntese de uma série de adaptações e melhorias implementadas na unidade produtiva visando a sua harmonia como um todo. Através dessa prática agrícola, o agricultor vai conseguindo ampliar a fertilidade do solo, intensificar a rotação e diversificação do sistema, diminuir o ataque de pragas e doenças, melhorar a conservação ambiental. Portanto, a cada novo patamar atingido pelo produtor, segundo o coeficiente do modelo, ocorre um acréscimo de $\mathrm{R} \$ 257,23 \mathrm{em}$ seu resultado líquido, podendo representar até um aumento de $\mathrm{R} \$ 771,69$ por mês, representando no conjunto uma das variáveis que mais contribuem para a geração líquida de resultados.

Através do uso de tecnologias (dentre elas a utilização de estufas e a integração das atividades) pode-se atingir eficiência técnico-agronômica e econômica. A utilização de tecnologias do sistema produtivo orgânico pode oferecer para os agricultores: ampliação da proteção do meio ambiente e da saúde das famílias, obtenção de maiores produtividades agrícolas e aumento da eficiência da força de trabalho.

\section{Conclusões}

As externalidades negativas da agricultura química convencional e as externalidades positivas da agricultura orgânica, consideradas lado a lado, destacam aspectos a serem considerados na definição de 
estratégias de desenvolvimento. O desafio da atualidade é garantir a segurança alimentar, com alimentos saudáveis, e o fornecimento dos insumos necessários para a economia, de forma socialmente justa e sem comprometer o meio ambiente e as gerações futuras. Esse comprometimento promoveu o amplo desenvolvimento da agricultura orgânica, acontecendo de forma muito intensa em outras partes do mundo, principalmente na União Européia. O Brasil não conseguiu ainda apresentar esta tendência, tendo apenas 0,24\% de sua área sob este sistema produtivo.

O objetivo deste estudo sobre a agricultura orgânica foi avaliar as dificuldades e as potencialidades brasileiras desta concepção produtiva. Para isso, são analisados os produtores olerícolas orgânicos da região metropolitana de Curitiba, identificando as suas características pessoais, técnicas e econômicas relevantes. Fatores relevantes desse conjunto de agricultores orgânicos são grau de instrução e outras experiências profissionais. Muito diferente da média brasileira, o grupo conta com uma distribuição de escolaridade com elevado percentual de agricultores com nível superior, bem como, mais da metade já tinha experiências com atividades de comércio ou serviços. A maior escolaridade e a elevada experiência fora da agricultura são fatores que diferem muito o grupo de conversão do grupo já certificado.

No entanto, esses não são fatores que excluem os produtores que não tenham essas habilidades, isto é, aqueles que tenham baixa escolaridade e experiência apenas agrícola. Não existe correlação significante entre o nível de escolaridade e outras experiências profissionais com o resultado líquido. Isto é, o desempenho agrícola não depende do produtor ser mais ou menos escolarizado, bem como independe de ter ou não outras experiências profissionais, em qualquer situação podem desenvolver a mesma capacidade de gerar resultado financeiro líquido.

Outro resultado importante da avaliação desse grupo de agricultores é a grande variação da composição das despesas totais. Essa oscilação indica que são possíveis duas alternativas para o crescimento da agricultura orgânica. A primeira forma é a agricultura orgânica com mínimo ingresso de insumos. Existe um grande potencial de desenvolvimento da agricultura orgânica com baixo uso de aquisições externas à fazenda e que vise o incremento da produção de qualidade e com 
produtividade. A segunda forma de desenvolver a agricultura orgânica é pela forma intensiva em tecnologias sustentáveis. Com uma visão empresarial, essa modalidade pode respeitar o meio ambiente, produzir alimentos saudáveis, trazer benefícios sociais de geração de empregos e dignidade no campo, sendo, ao mesmo tempo, uma opção lucrativa para agricultores com alta tecnologia orgânica. O estudo desse caso mostra que a agricultura capitalizada pode investir e colher os frutos com a agricultura orgânica.

A análise de regressão indica que é importante que as famílias agrícolas tenham desejos de prosperarem, pois os gastos da família é um fator que estimula a obtenção de resultados positivos. O conhecimento aplicado e a capacitação técnica são indispensáveis para elevar o nível técnico do produtor, independente da escolaridade formal e de outras experiências profissionais. Isso abre o caminho para o uso de tecnologias mais apropriadas de manejo, como o uso de estufas, e de integração da lavoura e da pecuária dentro do estabelecimento. A aquisição de conhecimentos técnicos independente da formação acadêmica, promove aumentos das produtividades através do manejo sustentável da agricultura orgânica e da maior utilização de mão-de-obra. Tudo isso induz a certificação orgânica, fator que agrega valor ao preço do produto vendido.

A agricultura orgânica, do ponto de vista governamental, é uma oportunidade de formulação de políticas públicas. O potencial brasileiro para a agricultura orgânica são os agricultores familiares excluídos da agricultura química. Essa modalidade pode contemplar, no mínimo, $70 \%$ dos agricultores brasileiros, aqueles que não possuem nenhuma força mecânica para realizarem suas atividades (FAO/INCRA, 2000). Políticas bem planejadas poderiam induzir o desenvolvimento desses agricultores marginalizados. É condição básica, no entanto, o agricultor ser devidamente capacitado. Conhecer os princípios da agricultura orgânica, os objetivos da visão da propriedade como um organismo, a integração da agricultura e da pecuária para fertilização do solo, a importância da biodiversidade, as práticas ecológicas de conservação e todos os outros conhecimentos para cultivar com eficiência técnica e econômica. 


\section{ReferênciaS bibliográficas}

ABRANTES, Luiz Antônio. Tipificação e caracterização dos produtores rurais através da utilização de informações contábeis. Lavras: UFLA, 1998.

ALTIERI, Miguel. Agroecologia: bases científicas para uma agricultura sustentável. Guaíba: Agropecuária, 2002.

ALTMANN, Rubens; OLTRAMARI, Ana Carla. A agricultura orgânica na região da grande Florianópolis: indicadores de desenvolvimento. Florianópolis: Instituto Cepa/SC, 2004.

BEZERRA, M.C.L.; VEIGA, J.E. (Coord.) Agricultura Sustentável. Brasília: Ministério do Meio Ambiente; Instituto Brasileiro do Meio Ambiente e dos Recursos Naturais Renováveis; Consórcio Museu Emílio Goeldi, 2000.

BRASIL. Ministério da Agricultura, Pecuária e Abastecimento. Instrução Normativa $\mathbf{N}^{0} 7$. Brasília: Diário Oficial da União, Seção 1. págs 11, 19/05/1999.

BRASIL. Lei 10.831. Brasília: Diário Oficial da União, 24/12/2003.

CHABOUSSOU, Francis. Plantas doentes pelo uso de agrotóxicos: a teoria da trofobiose. Porto Alegre: L\&PM, 1987

CHAYANOV, Alexander V. La organización de la unidad económica campesina. Buenos Aires: Nueva Visión, 1974.

DAROLT, M. R. As Dimensões da Sustentabilidade: Um estudo da agricultura orgânica na região metropolitana de Curitiba-PR. 2000. Tese (Doutorado em Meio Ambiente e Desenvolvimento) - Universidade Federal do Paraná e Universidade de Paris VII, Curitiba.

DAROLT, M. R. Agricultura Orgânica: inventando o futuro. Londrina: IAPAR, 2002.

EHLERS, Eduardo M. O que se entende por agricultura sustentável? 1994. Tese (Mestrado em Ciência Ambiental) - Programa de Pós-Graduação FEA/USP, São Paulo.

FAO/INCRA. Novo Retrato da Agricultura Familiar: o Brasil Redescoberto. Brasília, 2000. 
FREITAS, João Carlos de. Agricultura Sustentável: Uma análise comparativa dos fatores de produção entre Agricultura Orgânica e Agricultura Convencional. 2002. Dissertação (Mestrado em Economia) - Departamento de Economia. Universidade de Brasília, Brasília.

GRAZIANO NETO, F. Questão agrária e ecologia: crítica da moderna agricultura. São Paulo: Brasiliense, 1982.

HESS, Anselmo Antônio. Ecologia e produção agrícola. Florianópolis: ACARESC, 1980.

LIMA, Arlindo J.P. et al. Administração da unidade de produção familiar: modalidades de trabalho com agricultores. Ijuí: UNIJUÍ, 1995.

SMAILES, Joanne; McGRANE, Angela. Estatística aplicada à administração com Excel. São Paulo: Atlas, 2002.

USDA - Departamento de Agricultura dos Estados Unidos. Grupo de Estudos sobre a Agricultura Orgânica. Relatório e recomendações sobre agricultura orgânica. Brasília: CNPq, 1984.

VEIGA, José Eli da. 0 desenvolvimento agrícola: uma visão histórica. São Paulo: Editora da Universidade de São Paulo: HUCITEC, 1991.

Recebido em agosto de 2005 e revisto em abril de 2006 